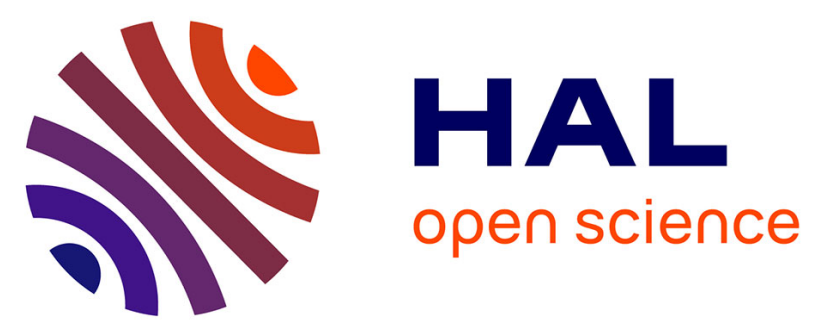

\title{
Eddy currents computation in translational motion conductive plate of an induction heater with consideration of finite length extremity effects
}

Mohammed Messadi, Larbi Hadjout, Youcef Ouazir, Hakim Bensaidane, Thierry Lubin, Smail Mezani, Abderrezak Rezzoug, Noureddine Takorabet

\section{To cite this version:}

Mohammed Messadi, Larbi Hadjout, Youcef Ouazir, Hakim Bensaidane, Thierry Lubin, et al.. Eddy currents computation in translational motion conductive plate of an induction heater with consideration of finite length extremity effects. IEEE Transactions on Magnetics, 2016, 52 (3), pp.6300304. 10.1109/TMAG.2015.2498762 . hal-01228329

\section{HAL Id: hal-01228329 \\ https://hal.science/hal-01228329}

Submitted on 12 Nov 2015

HAL is a multi-disciplinary open access archive for the deposit and dissemination of scientific research documents, whether they are published or not. The documents may come from teaching and research institutions in France or abroad, or from public or private research centers.
L'archive ouverte pluridisciplinaire HAL, est destinée au dépôt et à la diffusion de documents scientifiques de niveau recherche, publiés ou non, émanant des établissements d'enseignement et de recherche français ou étrangers, des laboratoires publics ou privés. 


\title{
Eddy Currents Computation in Translational Motion Conductive Plate of an Induction Heater with Consideration of Finite Length Extremity Effects
}

\author{
M. Messadi ${ }^{1}$, L. Hadjout ${ }^{1}$, Y.Ouazir ${ }^{1}$, H.Bensaidane ${ }^{1}$, T. Lubin $^{2}$, S. Mezani ${ }^{2}$, A. Rezzoug ${ }^{2}$ and N. Takorabet ${ }^{2}$ \\ ${ }^{1}$ LSEI-Université des Sciences et Technologie Houari Boumediene, BP N³2, 16111, Alger, Algérie \\ ${ }^{2}$ GREEN-Université de Lorraine, Faculté des Sciences et Technologies, BP 239, 54506, Vandœuvre-lès-Nancy, France
}

\begin{abstract}
An electromagnetic model is proposed to compute translational motion eddy current in a conductive plate. The eddy currents are due to the movement of the plate in a de magnetic field created by a PM inductor. Firstly, the magnetic field due to the PMs is computed in 3D where the iron yokes influence is considered thanks to the method of images. Then, the motional eddy currents are computed such that the edge effects are correctly taken into account through an iterative procedure which uses magnetic images. The computations are very fast and the obtained results are close to those issued from 3D FE method and from experiments.
\end{abstract}

Index Terms—eddy currents, induction heating device, method of images, linear motion.

\section{INTRODUCTION}

$\mathrm{I}_{\mathrm{i} i \mathrm{~s}}^{\mathrm{b}}$ NDUCTION heating is increasingly used in various industrial applications such as heat treatment and the assembly process. The well-known principle is based on the fact that any stationary conductor placed in a variable magnetic field is flowed by eddy currents creating Joule losses. Another induction heating process is to move the conductive plate in a static magnetic field [1], [2], [3].

This paper proposes an exact 3D electromagnetic model to compute heating power in the conducting plate of a novel translational motion heating device [1].

Two-dimensional models are widely used for the computation of induction heaters with rotating billets [2], [3]. However, such models are not suitable for the studied heater which exhibits strong edge effects. 3D models are then required [4], [5]. The finite element method is the preferred tool of analysis in 3D [6], [7]. Unfortunately, the CPU time is very important.

In [1], we have developed a 2D analytical model to compute the heating power in the studied device. In order to consider the edge effects, a correction factor has been used.

The present paper proposes an exact 3D electromagnetic model based on magnetic images theory. Compared to 3D FEM, our model gives very close results. Furthermore, this model leads to important savings in the computation time.

The studied device, Fig. 1, is composed of two permanent

Manuscript received 25 June 2015 . M. Messadi, L. Hadjout, Y. Ouazir, H. Bensaidane. are with LSEI-University of science and technology (USTHB), BP N³2 El Alia Bab Ezzouar, Algiers, Algeria (e-mail: messadi_m@yahoo.fr, lhadjout@yahoo.fr, youazir@yahoo.fr and hakimbensaidane@yahoo.fr).

T. Lubin, S. Mezani, A. Rezzoug and N.Takorabet are with GREENUniversité de Lorraine, BP 239, 54506, Vandouvre-lès-Nancy, France (email: Thierry.Lubin@univ-lorraine.fr, Smail.Mezani@univ-lorraine.fr, Abderrezak.Rezzoug@univ-lorraine.fr and Noureddine.Takorabet@univlorraine.fr) magnets (PM) inductors with quasi Halbach magnetization arrangement. A non-magnetic conducting plate (work-piece), which must be heated, is placed between these two inductors and is subjected to a linear oscillatory motion. The geometrical parameters of the studied device are given in Table. I.

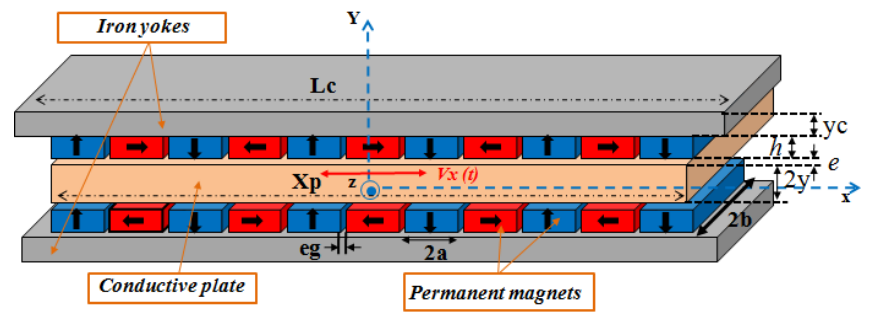

Fig.1. Geometry of the studied device.

\section{COMPUtATiOn MethoD}

Considering that the iron yokes have an infinite permeability, we can use the images theory. The calculation of the heating power in the conducting plate is carried out in three steps:

- Calculate the magnetic flux density created by the two PM inductors using images method;

- Calculate the eddy currents for an infinite conducting plate;

- Use the images method to consider the finite dimensions of this plate.

\section{A. Magnetic flux density}

In the first stage, we calculate the magnetic field produced by each PM separately. The Amperian model is used to represent the magnets whose magnetization is noted $\vec{M}$ :

$\overrightarrow{J_{s}}=\vec{M} \wedge \vec{n}$

Each PM can be replaced by four equivalent current sheets $\overrightarrow{J_{s}}$ placed on its lateral faces (Fig.2). In vacuum, the flux density $\overrightarrow{B_{p}}$ at a distance $r$ from an elementary surface $d s$ is determined using the Biot-Savart law [8]:

$$
\overrightarrow{B_{p}}=\frac{\mu_{0}}{4 \pi} \oiint \frac{\overrightarrow{J_{s}} \wedge \vec{r}}{r^{3}} d s
$$




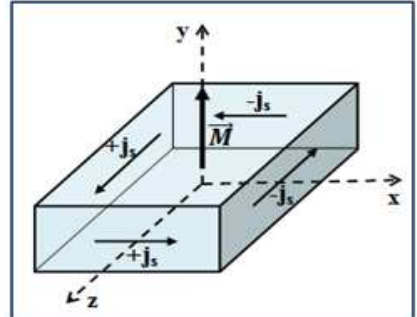

Fig.2 Amperian model of Permanent Magnet

Superposition method is then used to determine the overall solution.

To take into account the boundary conditions at the interfaces between the air and the ferromagnetic yokes, the images method is used. Starting from the solution given by (2) to compute the magnetic field in air, an iterative procedure allows the consideration of the ferromagnetic yokes. As shown in Fig.3, the principle consists of replacing the effects of a ferromagnetic plane by equivalent magnets behind the plane (called images); the total magnetic field is then obtained by the superposition of the fields due to the source magnet and its images. This procedure is used in an iterative way to compute the magnetic field due to all PM's images [8], [9], [10].

For the studied device, the use of the above procedure leads, for each PM block, to the flux density components in free air given by (3) and (4) respectively for magnet with normal(y component) magnetization and for magnet with tangential $(x$ component) magnetization.

$$
\begin{gathered}
B_{x}=\frac{-\mu_{0} j_{s}}{4 \pi} \sum_{i, j, k=0}^{1}(-1)^{i+j+k} \operatorname{Ln}(Z+R) \\
B_{y}=\frac{-\mu_{0} j_{s}}{4 \pi} \sum_{i, j, k=0}^{1}(-1)^{i+j+k}\left[\tan ^{-1}\left(\frac{Y Z}{X R}\right)+\tan ^{-1}\left(\frac{X Y}{Z R}\right)\right] \\
B_{z}=\frac{-\mu_{0} j_{s}}{4 \pi} \sum_{i, j, k=0}^{1}(-1)^{i+j+k} \operatorname{Ln}(X+R) \\
\left\{\begin{array}{c}
B_{x}=\frac{-\mu_{0} j_{s}}{4 \pi} \sum_{i, j, k=0}^{1}(-1)^{i+j+k}\left[\tan ^{-1}\left(\frac{X Z}{Y R}\right)+\tan ^{-1}\left(\frac{X Y}{Z R}\right)\right] \\
B_{y}=\frac{-\mu_{0} j_{s}}{4 \pi} \sum_{i, j, k=0}^{1}(-1)^{i+j+k} \operatorname{Ln}(Z+R) \\
B_{z}=\frac{-\mu_{0} j_{s}}{4 \pi} \sum_{i, j, k=0}^{1}(-1)^{i+j+k} \operatorname{Ln}(Y+R)
\end{array}\right.
\end{gathered}
$$

Where for a point $P$ having the coordinates $\left(x_{m}, y_{m}, z_{m}\right)$ :

$$
\begin{aligned}
& X=\left(x_{m}-(-1)^{i} a\right) ; Y=\left(y_{m}-(1-j) \mathrm{h}\right) ; \\
& Z=\left(z_{m}-(-1)^{k} b\right) ; R=\sqrt{X^{2}+Y^{2}+Z^{2}}
\end{aligned}
$$

$a, b$ and $h$ is the magnet dimensions as shown in Fig.1.

The air gap flux density produced by all the magnet blocks of the studied device of Fig. 1 is then:

$$
\begin{aligned}
\overrightarrow{B_{m}}\left(x_{m}, y_{m}, z_{m}\right)= & \sum_{i=0}^{\mathrm{Nr}-1}\left(\sum_{n=0}^{\infty} \overrightarrow{B r}_{n}\left(\left(X_{m}, y_{m} \pm H_{n}, z_{m}\right)\right)\right. \\
& +\sum_{i=0}^{\mathrm{Nt}}\left(\sum_{n=0}^{\infty}(-1)^{\mathrm{n}} \overrightarrow{B t}_{n}\left(\left(X_{m}, y_{m} \pm H_{n}, z_{m}\right)\right)\right.
\end{aligned}
$$
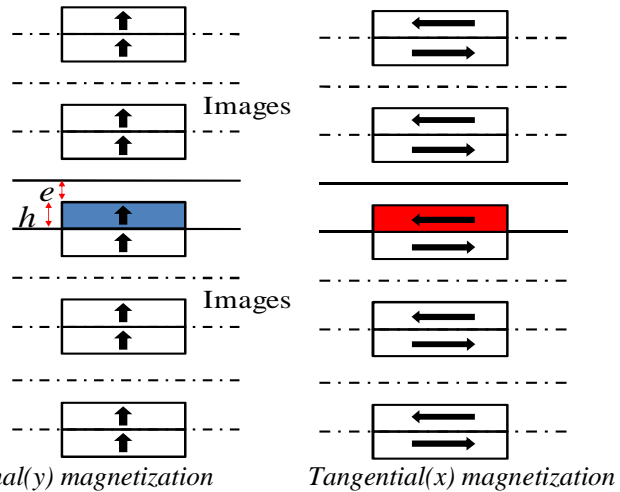

Normal(y) magnetization

Fig.3. Principle of the images method.

with $X_{m}=x_{m}+2 i\left(a+e_{g}\right)$ for PM with normal(y component) magnetization and $X_{m}=x_{m}+(2 i+1)\left(a+e_{g}\right)$ for PM with tangential ( $x$ component) magnetization. $e_{g}$ is the distance between two magnet (Fig.1).

We can distinguish four sets of PM's images. Their heights are:

$\left\{\begin{array}{lll}H_{n}=\left(\frac{-n+3}{2}\right) h+\left(\frac{-n+1}{2}\right) e & n=4 k+1 & k=0: \infty \\ H_{n}=\frac{-n+2}{2}(h+e) & n=4 k+2 & k=0: \infty\end{array}\right.$

for $y<y_{m}$, and

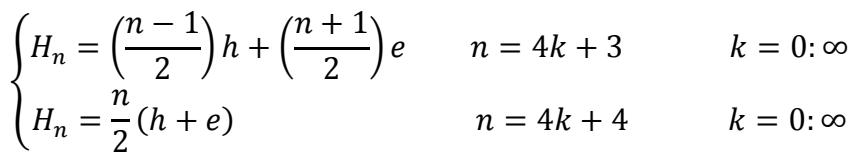

for $y>y_{m}$, where:

$N_{r}$ and $N_{t}$ are the total number of PM's with normal and tangential magnetization, respectively, $\overrightarrow{B r}_{n}$ is the flux density due to normally magnetized PMs, $\overrightarrow{B t}_{n}$ is the flux density due to tangentially magnetized PMs, $n$ and $H_{n}$ represent the number and the height of the PM image, respectively.

\section{B. Eddy current expressions in the conductive plate}

To obtain a homogeneous distribution of the temperature in the plate, its velocity should be low (typically $1 \mathrm{~m} / \mathrm{s}$ ). Hence, the reaction field due to the induced currents in the plate can be neglected. The eddy currents in the conducting plate are then computed using:

$\overrightarrow{\operatorname{curl}}\left(\overrightarrow{J)}=-\sigma \frac{\partial \overrightarrow{B_{m}}}{\partial t}\right.$

where $\sigma$ is the electric conductivity of the plate.

$\left\{\begin{array}{l}\frac{\partial J_{z}}{\partial y}=-V_{x}(t) \sigma \frac{\partial B_{m x}}{\partial x} \\ \frac{\partial J_{x}}{\partial y}=V_{x}(t) \sigma \frac{\partial B_{m z}}{\partial x}\end{array}\right.$

where $V_{x}(t)$ is the velocity of the conducting plate.

From (7), the induced current density components in the conductive plate, due to one block PM placed in air are given by (8) and (9) for PM with normal (y component) magnetization and PM with tangential ( $x$ component) magnetization respectively. 
TABLE I

GEOMETRIC PARAMETERS OF THE INDUCTION HEATER

\begin{tabular}{lll}
\hline \hline Symbol & \multicolumn{1}{c}{ Designation } & Value \\
\hline $2 y_{1}$ & Conducting plate thickness & $15 \mathrm{~mm}$ \\
$X_{p}$ & Conducting plate length & $200 \mathrm{~mm}$ \\
$Z_{p}$ & Conducting plate width & $50 \mathrm{~mm}$ \\
$e$ & Air-gap thickness & $3 \mathrm{~mm}$ \\
$h$ & Permanent magnet thickness & $10 \mathrm{~mm}$ \\
$a$ & Permanent magnet width & $20 \mathrm{~mm}$ \\
$b$ & Permanent magnet length & $50 \mathrm{~mm}$ \\
$e_{g}$ & Distance between two magnets & $2 \mathrm{~mm}$ \\
$y_{c}$ & Iron yoke thickness & $20 \mathrm{~mm}$ \\
$L_{c}$ & Iron yoke length & $400 \mathrm{~mm}$ \\
$Z_{c}$ & Iron yoke width & $60 \mathrm{~mm}$ \\
$V_{x}(t)$ & Oscillatory linear velocity & variable \\
$v_{\max }$ & Velocity peak value & variable \\
$B_{r}$ & Remanent flux density of PM & $1.21 \mathrm{~T}$ \\
\hline
\end{tabular}

$\left\{\begin{array}{c}J_{x}=\frac{V_{x} \sigma \mu_{0} j_{s}}{4 \pi} \sum_{i, j, k=0}^{1}(-1)^{i+j+k} \operatorname{Ln}(2 Y+2 R) \\ J_{z}=\frac{-V_{x} \sigma \mu_{0} j_{S}}{4 \pi} \sum_{i, j, k=0}^{1}(-1)^{i+j+k}\left[\tan ^{-1}\left(\frac{Y}{X}\right)-\tan ^{-1}\left(\frac{Z Y}{X R}\right)\right]\end{array}\right.$

$$
\left\{\begin{array}{c}
J_{x}=\frac{V_{x}(t) \sigma \mu_{0} j_{s}}{4 \pi} \sum_{i, j, k=0}^{1}(-1)^{i+j+k}\left(\frac{X(Y-R)}{X^{2}+Z^{2}}\right) \\
J_{z}=\frac{-V_{x}(t) \sigma \mu_{0} j_{s}}{4 \pi} \sum_{i, j, k=0}^{1}(-1)^{i+j+k}\left[-\tanh ^{-1}\left(\frac{R}{Z}\right)+\left(\frac{Z R}{X^{2}+Z^{2}}\right)\right]
\end{array}\right.
$$

In (8) and (9) $X$ is given by $X=\left(x_{m}-(-1)^{i} a\right)+x_{p}(t)$, where $x_{p}(t)$ is the plate position versus inductors frame. It is derived from:

$$
\frac{d x_{p}(t)}{d t}=V_{x}(t)
$$

For the actual device, the conducting plate has finite dimensions, so the normal components of the eddy current densities vanish on its lateral faces. To satisfy these boundary conditions with the concept of images method [5], [11], an infinite number of images can be introduced outside the plate ( $x$ and $z$ directions) (Fig.4). Thus, the actual eddy current density produced in a point of the plate is the superposition of the source eddy current density (infinite plate) and the eddy current densities of the images. The resulting eddy current density, $\overrightarrow{J_{\text {tot }}}$, is then written as:

$\overrightarrow{J_{t o t}}=\sum_{n=-\infty}^{\infty} \sum_{m=-\infty}^{\infty}(-1)^{n-m} \vec{J}\left(x_{m}+n X_{p}, y_{m}, z_{m}+m z_{p}\right)$

$n$ and $m$ are the numbers of eddy current images along the $x$ and y directions. The heating power $P(t)$ dissipated by Joule effect in the conducting plate is computed by the integration of the power density in the volume of the plate:

$$
P(t)=\int_{-X_{p} / 2}^{X_{p} / 2} \int_{-Z_{p} / 2}^{Z_{p} / 2} \int_{-Y_{p} / 2}^{Y_{p} / 2}\left(\frac{J_{x}^{2}+J_{z}^{2}}{\sigma}\right) d x d z d y
$$

$X_{p}, Y_{p}$ and $Z_{p}$ are the plate dimensions (Fig.1).

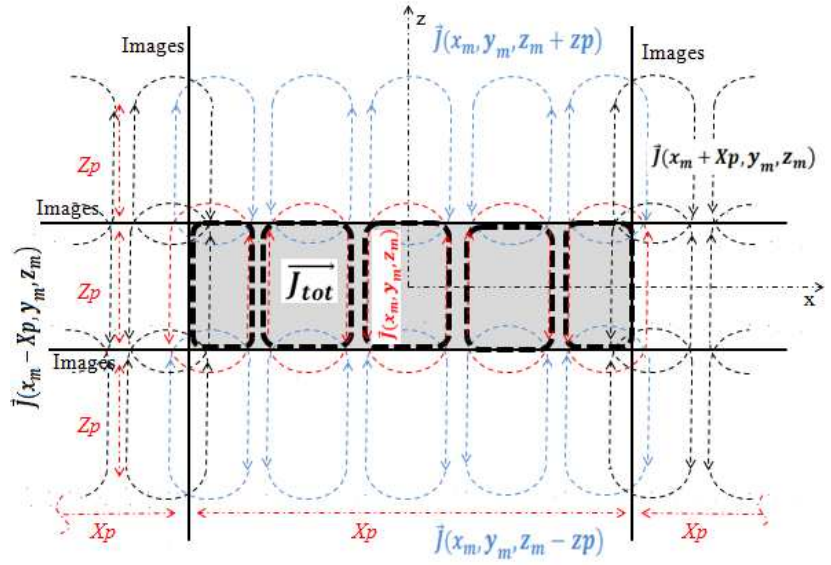

Fig.4.The current densities involved for one layer of images

\section{RESULTS}

The results of our model have been compared to FE simulations as well as to some measured data. The test rig of the studied induction heater is shown in Fig.5.

The normal and tangential air gap flux densities distribution in the middle of the air-gap $\left(y=y_{1}+e / 2\right)$, are presented in Fig.6. and Fig.7. The considered device has 6-poles and produces a $0.6 \mathrm{~T}$ peak value for the $\mathrm{y}$-component of the air gap flux density. The comparison with FE and experimental results is given in Fig.7.a and Fig.7.b. These figures give the ycomponent of the flux density in the $x-y$ plane along the $x-$ direction and z-direction, respectively. It can be seen that the flux density waveforms predicted by the proposed 3D model are very close to the FE predictions and to the experiments.

Note that the number of images is theoretically infinite. However, only 10 iterations are needed to converge to a stable solution.

The computations of the eddy currents are performed for the aluminum conducting plate of dimensions $X_{p}=0.24 \mathrm{~m}, Z_{p}=$ $0.05 \mathrm{~m}$. The plate is subjected to an alternating linear motion in the $x$ direction with a velocity peak value $\mathrm{V}_{\mathrm{x}}=0.5 \mathrm{~m} / \mathrm{s}$.

To show the importance of considering the edge effects, we have computed the current density distribution for an infinite plate length (computed without images current) and for the actual finite length plate (computed with images current). To compare the obtained results to the 3D FE predictions, the current density waveforms are plotted along the $x$ and $z$ directions in the $x-z$ plane at $\mathrm{y}=0$. As it can be seen from Fig.8.a and Fig.8.b, neglecting the edge effects leads to incorrect results. Indeed, for the $\mathrm{J}_{\mathrm{x}}$ component (Fig.8.a), the peak value is about $3.5 \mathrm{~A} / \mathrm{mm}^{2}$ (our model without images) while accounting for the finite length results in a peak value of about $6 \mathrm{~A} / \mathrm{mm}^{2}$ (our model with images and 3D FE). For the $\mathrm{J}_{\mathrm{z}}$ component (Fig.8.b), the peak values are about $7.5 \mathrm{~A} / \mathrm{mm}^{2}$ (our model without images) and $5.5 \mathrm{~A} / \mathrm{mm}^{2}$ (our model with images and 3D FE), respectively. Furthermore, the proposed model with images gives very similar results compared to the 3D FE analyses.

Notice that to reach a stable solution, only 4 images in the $z$ direction and two images along the $x$ direction are required. 
Regarding the heating power, we have compared the measured values to the computed ones which have been obtained with the different methods in use (3D FE, our method with and without images).

The results are shown in Fig.9 for several peak velocity values. Again, it can be seen that neglecting the finite length effects leads to an over estimation of the heating power (about $60 \%$ difference compared to the measured value at $1 \mathrm{~m} / \mathrm{s}$ ). Our model (with images) gives very close results compared to the 3D FE predictions and to the measurements (less than 5\% difference).The computation time (for a given value of the velocity) is $196 \mathrm{~s}$ for the 3D FEM (work station $48 \mathrm{~Gb}, 2$ processors, 16core), whereas the computing time for the proposed method is about 50 s on a desktop PC( $2 \mathrm{~Gb}$, Intel core duo).

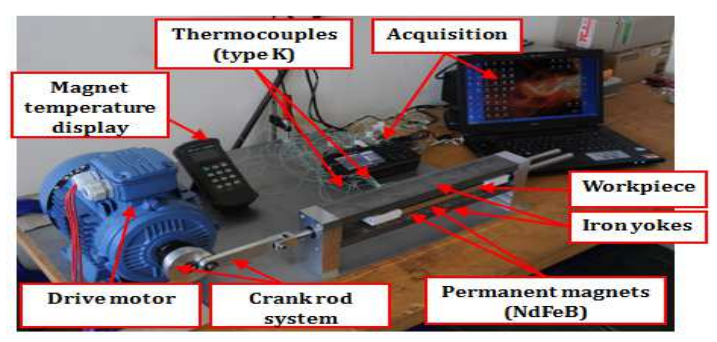

Fig.5. Induction heater prototype, measurements and data acquisition

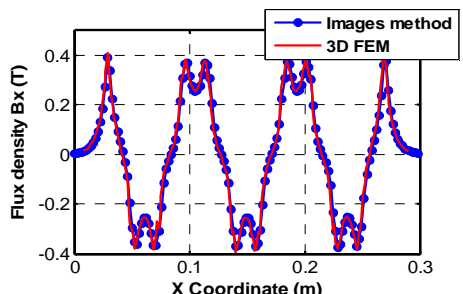

(a)

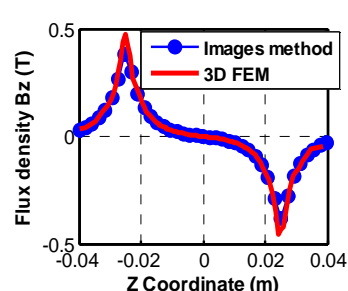

(b)
Fig.6: Tangential flux density components distribution in middle of air-gap (a) versus the $\mathrm{x}$-coordinate; (b) versus the $\mathrm{z}$-coordinate.

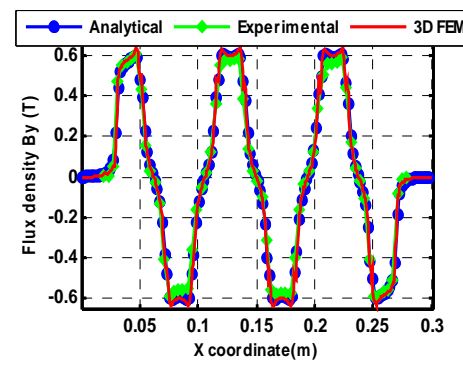

(a)

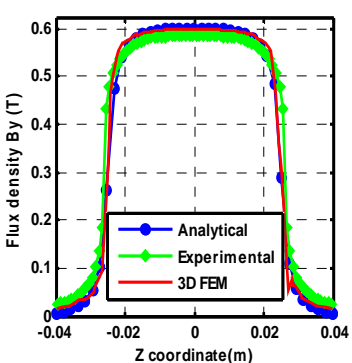

(b)
Fig.7: Normal flux density $\left(\mathrm{B}_{\mathrm{y}}\right.$ in middle of air-gap: (a) versus the $\mathrm{x}$ coordinate; (b) versus the $\mathrm{z}$-coordinate.

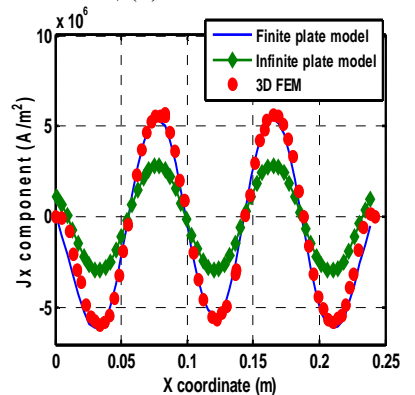

(a) $\mathrm{J}_{\mathrm{x}}$ component

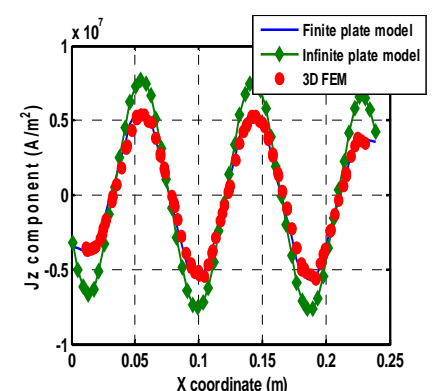

(b) $\mathrm{J}_{\mathrm{z}}$ component
Fig.8: Induced Current density in the conducting plate (Velocity $=0.5 \mathrm{~m} / \mathrm{s}$ )

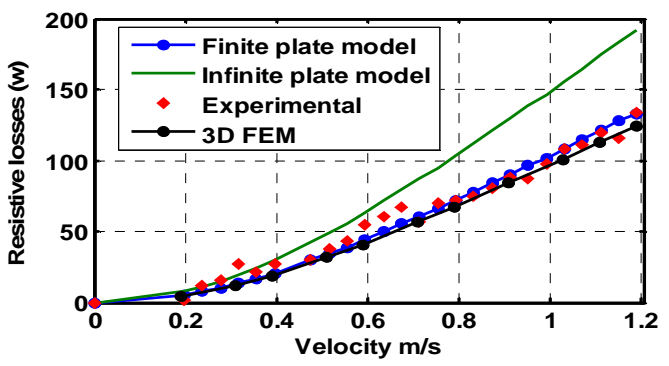

Fig.9: Heating power in the conducting plate.

\section{CONCLUSION}

A 3-Delectromagnetic model based on the theory of images is developed for calculating the static magnetic field distribution produced by a permanent magnet (PM) inductor and the resulting translational motion eddy currents in a conductive plate.

The results show the effectiveness of the model to properly account for finite length effects. Indeed, the obtained results are very close to those obtained from 3-D FEM and experiments with the benefit of important reduction in the computation time. This is of great importance in any parametric or optimization study where quick and flexible models are needed.

\section{REFERENCES}

[1] H.Bensaidane, T.Lubin, S.Mezani, Y.Ouazir, and A.Rezzoug, "A New topology for induction heating system with PM excitation: electromagnetic model and experimental Validations" IEEE Trans. Magn., vol. 51, no. 10, October 2015.

[2] M. Fabbri, A. M. Forzan, S. Lupi, A. Morandi, and P. L. Ribani, "Experimental and numerical analysis of DC induction heating of aluminum billets,"IEEE Trans. Magn., vol. 45, no. 1, pp. 192-200, Jan. 2009.

[3] T. Lubin, D. Netter, J. Leveque, and A. Rezzoug, "Induction heating of aluminum billet subjected to a strong rotating magnetic field produced by superconducting windings," IEEE Trans. on Magn., vol. 45, no 5, pp. 2118-2127, May 2009

[4] S.Paul, J.Wright, and J.Z.Bird, "3-D steady-state eddy current damping and stiffness for a finite thickness conductive plate,"IEEE Trans.Magn., vol. 50,no.11,pp. 6301404, November 2014.

[5] Jun.H. Zhang and al, "Modeling and analysis of a novel planar eddy current damper,"Journal of Applied Physics 115, 17E709,January 2014.

[6] A.H.Selçuk ,H. Kürüm, "Investigation of end effects in linear induction motors by using the finite element method," IEEE TransMagn, vol. 44, No. 7,pp1791-1795, July 2008.

[7] O.Bíró, G; Koszka and K. Preis,"Fast time-domain finite element analysis of 3-D nonlinear time periodic eddy current problems with Т,Ф-Ф formulation", IEEE Trans.Magn, vol 45, no. 5, pp.1170-1173, May 2011.

[8] K. J. Binns and P. J. Lawrenson, "Analysis and Computation of Electricand Magnetic Field Problems, " 2nd ed. New York: Pergamon, 1973.

[9] J.M.M.Rovers, J.W.Jansen and O.A.Lomonova,"Modeling of relative permeability of permanent magnet materiel using magnetic surface charges, "IEEE Trans.Magn., vol.49, no. 6, pp.2913-2919, June 2013.

[10] Sang-Ho Lee and al, "Characteristic analysis of the slotless axial-flux type brushless DC motors using image method, "IEEE Trans.Magn., vol.42.no.4, pp.1327-1330, April 2006.

[11] K. J. W. Pluk, T. A. van Beek, J. W. Jansen, and E. A. Lomonova, "Modeling and Measurements on a Finite Rectangular Conducting Plate in an Eddy Current Damper,"IEEE Trans. Industrial Electronics, vol 61, no.8, pp4061-4072, August 2014. 